\title{
Capítulo I Ser ciudadano: La ciudad de las luces
}

\section{El ser humano necesita de los demás para sobrevivir}

Platón cuenta en uno de sus diálogos la particular creación de los seres vivos por los dioses griegos. Primero, se ocuparon de los animales y procuraron que nacieran con los pertrechos imprescindibles para poder sobrevivir: unos vinieron al mundo dotados de fuerza, otros de astucia o de velocidad o siendo diminutos para pasar desapercibido o muy grandes para disuadir a los violentos. Solo el ser humano nació desnudo, descalzo, sin ningún tipo de defensas incorporadas. Cuando Prometeo vio aquello, no le pareció justo, de ahí que ni corto ni perezoso robara a los dioses el fuego y lo que ellos sabían hacer con el fuego para entregárselo a los seres humanos. Con el arte del fuego los humanos podían hacer armas y de esa manera se equilibraba la competencia entre seres vivos. Y no hubo sorpresa cuando advirtió que con esas armas los humanos se defendían, desde luego, eficazmente contra las bestias, aunque también que se destruían entre ellos. Los dioses temieron, entonces, que la raza humana pudiera sucumbir, de ahí que decidieran enviar con toda presteza al más rápido de todo ellos para "que trajera a los hombres el sentido moral y la justicia para que hubiera orden en las ciudades y convivencia acorde con la amistad" (Protágoras).

Lo que nos cuenta el relator de esta historia, el maestro Protágoras, es que el ser humano necesita de los demás para sobrevivir; es decir, los humanos no podemos 
sobrevivir sin convivir. Y las bases de la convivencia son las dos virtudes que los dioses nos conceden a todos, a saber, la conciencia moral y la justicia; el sentido de lo bueno y de lo justo. Lo que, en definitiva, se nos dice es que la base de la convivencia no son las armas sino las virtudes cívicas.

Hablar hoy de virtudes parece arcaico. Relacionamos al ser virtuoso con el ser religioso y la religión, ya se sabe, es un asunto personal, íntimo, privado. ¿Cómo se les ocurrió a los griegos recurrir a las virtudes para explicar la convivencia ciudadana? Ellos entendían que las virtudes eran esas cualidades o valores que el ser humano tiene que hacer suyas, si pretendían lograrse, si querían dar de sí todo lo que llevaban dentro.

Las virtudes se adquieren mediante la educación y el ejercicio. Nadie nace siendo justo o prudente. El exigente aprendizaje de las virtudes consta de dos capítulos: información y práctica. Primero, hay que instruirse en lo que, por ejemplo, significa ciudadanía, un concepto que se ha ido elaborando poco a poco y que hoy, en plena democracia del siglo XXI, tiene una densidad característica. Pero luego hay que llevarlo a la práctica en la vida diaria, si queremos realmente adquirir la virtud cívica. En el relato platónico que hemos evocado se dice que las virtudes cívicas la conciencia moral y la justicia - son un regalo del cielo; es decir, que cualquiera puede acceder a ellas, si lucha por ellas. Lo que se nos quiere decir es que cuando se trata de algo que atañe al gobierno de la ciudad vale lo mismo la palabra de un carpintero que la de un herrero, un curtidor, un mercader, un navegante, un rico o un pobre. Lo que hay que saber para convivir o ser ciudadano está al alcance de todo el mundo. Basta con querer saberlo y con tener voluntad para ponerlo en práctica.

Notemos que aunque las virtudes cívicas estén al alcance de todo el mundo, eso no significa que todo el mundo se haya molestado en aprenderlas y practicarlas. El político ateniense Pericles se refiere a ello en un memorable discurso:

\footnotetext{
Tenemos un régimen político que no emula las leyes de otros pueblos, y más que imitadores de los demás, somos un modelo a seguir. Su nombre, debido a que el gobierno no depende de unos pocos, sino de la mayoría, es democracia. En lo que concierne a los asuntos privados, la igualdad, conforme a nuestras leyes, alcanza a todo el mundo, mientas que en la elección de cargos públicos no anteponemos las razones de clase al mérito personal; y tampoco nadie en razón de su pobreza encuentra obstáculos debido a la oscuridad de su condición social si está en condiciones de prestar un servicio a la ciudad(...) Somos en efecto los únicos que a quien no toma parte en los asuntos de la ciudad lo consideramos no como un despreocupado sino como un inútil porque, en nuestra opinión no son las palabras lo que supone un perjuicio (...) sino el no (...) proceder a lo necesario mediante la acción" (Tucídides).
}

Los atenienses eran unos raros al tomarse tan en serio la igualdad de todos ante el poder y la participación ciudadana. No distinguían entre pobres y ricos a la hora de contar con fuerzas vivas para el gobierno de la ciudad y tampoco celebraban a quienes no echaban una mano en los asuntos públicos porque consideraban 
que ocuparse de lo que es común es una pérdida de tiempo. A estos les llamaban "idiotas", gente que va a lo suyo. Lo que caracterizaba a la ciudadanía ateniense era esa conjugación del principio de "igualdad de derechos" (isonomía) con el de "igualdad de palabra" (isegoría): la misma ley para todos y todos con la misma capacidad de decidir. Todos, pues, eran legisladores y todos igualmente súbditos de la ley acordada.

Para ser justos con la democracia ateniense hay que hacer dos puntualizaciones. La primera, que era una democracia muy limitada. Hablamos con mucha soltura de "todos", pero eran unos pocos: para empezar, tenían que ser varones, libres, adultos y atenienses. No formaban parte de esa ágora democrática las mujeres, los esclavos, los niños o los extranjeros. Habida cuenta de que Atenas era una ciudad de unos 300.000 habitantes y que la inmensa mayoría no reunía las condiciones para ser ciudadanos, se puede estimar su número en torno a 6.000. Entre ellos, eso sí, todo iguales; pero superiores respecto a todos los demás, a los que tenían por súbditos y no por conciudadanos. La ciudadanía tiene ahí, en la pregunta de quién es ciudadano, un largo camino por recorrer.

La segunda puntualización se refiere a la naturaleza de la virtud cívica en los griegos. La polis o la cives o, como diríamos ahora, "la nación" era tan importante que la conducta individual, si quería ser buena o virtuosa, tenía que ajustarse a las leyes, a las costumbres o a los intereses de la misma. La libertad de decidir sobre asuntos de interés público tenía que ajustarse a las leyes de la ciudad. Eso podía llevar a serios conflictos entre los intereses de la nación y las exigencias de la propia conciencia. Sócrates, un gran ciudadano ateniense, modélico desde el punto de vista moral, fue condenado a muerte porque su moral iba contra las leyes de Atenas. El dramaturgo Esquilo inmortalizó ese conflicto entre la conciencia y las leyes en la tragedia Antígona. Ahí, Antígona desafía la voluntad del rey porque entiende que su orden va contra los dictados de su conciencia. El rey Creonte decidió, en efecto, que el cuerpo de su hermano muerto no fuera enterrado como mandan los dioses, sino que fuera arrojados extramuros de la ciudad para que fuera pastos de los buitres. Antígona prefiere seguir su conciencia, desafiando la ley de la ciudad, lo que significaba morir ahorcada.

Lo que de aquí se desprende es que la ciudadanía, tal y como la entendían los griegos, es decir, como virtud cívica, tiene un recorrido limitado por el punto de partida. Los ciudadanos griegos no pueden, en efecto, hacer que la voluntad popular sea ley. Esa voluntad tiene que amoldarse a unos principios previos que son las leyes antiguas o las costumbres consagradas de Atenas. Uno no puede ir por libre sino que su libertad es la vida libre "con los padres, hijos y sobre todo con los amigos y conciudadanos". Como luego diría un filósofo alemán, Federico Hegel, "los antiguos eran éticos pero no morales"; es decir, podían ser buenos ciudadanos si ponían en sintonía su libertad con los intereses de la ciudad, pero no podían permitirse cuestionar la autoridad de las leyes de la ciudad en nombre de los dictados de su conciencia. Para los griegos, ser bueno era ser buen ciudadano, es decir, someterse a los usos, costumbres y leyes de la ciudad. ¿Y qué pasaba si uno quería cambiar las leyes? Pues que se preparaba un buen conflicto. Al fin y al 
cabo, cambiar las leyes es una forma de decir que las que hay no son buenas y, por lo tanto, no merecen ser respetadas.

Aristóteles, que era uno de esos ciudadanos convencidos de que Atenas había llegado a un punto en el que "lo mejor era cambiar", tuvo que hacer grandes equilibrios para casar la necesidad del cambio con el respeto a las leyes existentes. Lo explicó recurriendo a la idea de que la ciudad, igual que un ser vivo, tiene una infancia, una época adulta y un momento de decrepitud. No hay que pensar, entonces, que lo más antiguo fuera lo mejor porque nuestros antepasados habitaran más cerca de los dioses que nosotros. Lo pasado era la infancia y lo que a ella sigue puede ser la madurez, de ahí que sea necesario adaptar las leyes a los nuevos tiempos sin que esa adaptación haya que interpretarla como desprecio a las leyes anteriores, sino tan solo como el desarrollo de ese núcleo de partida que llamamos naturaleza.

Como bien se puede observar, incluso en estos progresistas, el cambio tenía que atenerse a lo que pedía la naturaleza de la ciudad, que no es estable sino que está en movimiento, en tensión hacia su fin o perfección. El ser humano no podía permitirse muchos experimentos sobre cómo organizarse políticamente porque las reglas de la política ya estaban dadas por la naturaleza de la ciudad.

\section{Los débiles son excluidos}

Estas dos limitaciones que hemos señalado - a saber, que la democracia ateniense era para pocos y que la voluntad del individuo no podía enfrentarse a la autoridad de las leyes, so pena de muerte - indican ya cuáles obstáculos tendrá que superar el concepto de ciudadanía, si quiere llegar a un punto de madurez todavía no alcanzado.

Hay un momento en la historia de Europa en el que se dan las condiciones para afrontar con posibilidades de éxito esos dos obstáculos que vienen de lejos. Ese momento de madurez histórica le conocemos como "modernidad", lo situamos en el siglo XVIII y está caracterizado por una mentalidad que llamamos "Ilustración" o "Iluminismo". Este periodo se presenta a sí mismo como un tiempo o iluminado, por oposición a otros tiempos oscuros u oscurantistas en los que no brillaba la luz de la razón. Entonces, un párroco berlinés tuvo la feliz idea de preguntar a los más famosos pensadores alemanes qué era eso de lo que tanto se hablaba, qué era la Ilustración. De todas las respuestas, una, la que dio el filósofo Immanuel Kant, se ha convertido en cita obligada: 
Según este texto, la Ilustración sería el tiempo de madurez de la humanidad porque se atreve a pensar por su cuenta. Es un tiempo que clausura un largo periodo de la humanidad en el que el ser humano, en vez de pensar, daba por bueno todo lo que la religión le decía. Esa época de inmadurez era, a diferencia de la infancia biológica, culpable porque el ser humano disponía de la razón, pero no se atrevía a hacer uso de ella. Eso debe acabarse. Hay que atreverse a pensar libremente. Hay que hacer uso público de la razón. Ese es el signo de los nuevos tiempos que también llamamos "modernidad".

¿Pero qué significa pensar por cuenta propia o hacer uso público de la razón? Lo explica el mismo Kant en el Prefacio a la Crítica de la Razón Pura:: "nuestra época es la época de la crítica a la que todo debe ser sometido. Hay quien -como la religión - trata de sustraerse a ella en nombre de su santidad, su legislación y su majestad. Pero esa postura acarrea la justa sospecha contra ella y entonces no puede esperar respeto de la razón, algo que solo se otorga a quien pase el examen de la crítica libre y pública" (cf Reyes Mate, 1973).

Pensar por cuenta propia significa someter a crítica, a la crítica de la razón, todo lo que circule entre nosotros como verdad indiscutible, por ejemplo, la religión. Si la religión quiere presentarse ante la humanidad como verdadera, tendrá que cambiar de estrategia. Ya no vale decir que es verdadera porque Dios lo ha revelado; ahora tendrá que pasar por taquilla y someterse al examen "público y crítico" de la razón. El cambio es mayúsculo, pero si se mira bien afecta no solo a la religión sino también a las leyes de la ciudad que en Atenas se presentaban ante los ciudadanos como inviolables y dotadas de una autoridad propia. También las leyes de la ciudad tendrán que pasar por taquilla y someterse a la autoridad de la razón. Antígona ha encontrado, veinticinco siglos después de su desafío a la autoridad vigente, un aliado de primer orden.

Tenemos, pues, que el ser humano moderno lleva en sus genes la responsabilidad de construir el mundo; es decir, de organizar la convivencia partiendo del uso crítico y libre de la razón. Eso significa que a partir de ahora los cimientos de la política no pueden ser impuestos por ninguna autoridad extraña al ser humano la religión o las leyes heredadas -, sino que tienen que ser decididos por él mismo.

El ser humano es autónomo y, al mismo tiempo, responsable de lo que ocurre en el mundo. En esta última afirmación se esconden los dos grandes principios del ser moderno, a saber, el de autonomía y el de universalidad, dos principios que son vitales a la hora de dar una respuesta a esos problemas que la humanidad arrastra desde los tiempos antiguos (recordémosles: la democracia ateniense era para pocos y la voluntad del individuo no podía enfrentarse a la autoridad de las leyes, so pena de muerte). Autonomía significa que el único legislador legitimado para hacer leyes que exijan la obediencia del ser moderno es el propio ser humano. Por supuesto, una comunidad necesita leyes que hay que cumplir, pero a un ser libre solo le puede exigir obediencia su propia decisión libre; es decir, las leyes que él mismo se ha impuesto con los demás, por supuesto. Si yo soy libre, los demás también, y juntos decidimos lo que sea bueno para todos; es decir, las leyes que 
nos deben regir. Ahí asoma el segundo principio: el de la universalidad. Lo que yo decida libremente; si ello busca alcanzar la categoría de "moral" no basta que solo sea bueno para mí: debe serlo también para los demás. Bueno es aquello que siendo bueno para mí lo sea también para los demás; buena es aquella decisión mía que de alguna manera compromete a toda la humanidad.

Lo que se desprende del doble principio ilustrado es que en una sociedad moderna, construida bajo la inspiración ilustrada, todos los seres humanos tenemos que ser al mismo tiempo legisladores y súbditos. Somos legisladores porque nada nos puede obligar si no es decidido por nosotros mismos: no hay autoridad superior a nuestra propia voluntad. Eso es exactamente lo que decimos cuando afirmamos que el pueblo es soberano o cuando se escriben leyes como la Constitución española, cuyo primer artículo estipula que "la soberanía nacional reside en el pueblo español del que emanan los poderes del Estado". Y al mismo tiempo, todos súbditos en el sentido en que todos quedamos sometidos al imperio de la ley porque la ley no es el resultado de una voluntad libre que se impone sobre los demás, sino de todas nuestras libertades conscientes de que la libertad encuentra su grado de bondad cuando toma una decisión teniendo en cuenta el bien de todos.

Si todos somos legisladores y todos súbditos, podemos, entonces, encarar de una manera nueva los dos problemas políticos que tenemos pendientes. Si todos somos legisladores, se acabará con la idea de que solo pueden ser ciudadanos una élite de privilegiados. Y si todos tenemos que someternos a lo que libremente decidamos, el rey de Tebas estará en la misma posición que la ciudadana Antígona. De entrada, vale tanto la voluntad de uno como de la otra. Y lo que convierte a la voluntad de cada cual en ley es su dimensión universalista, esto es, su capacidad de incluir a los demás, de tener en cuenta los intereses de los demás a la hora de fijar el suyo propio.

\section{Nacemos iguales y libres}

No se piense que todo esto son solo ideas. Convendría recordar, a propósito de las ideas, aquella historia del escritor inglés Thomas Carlyle, donde hablaba el hombre de letras con un banquero suizo sobre lo divino y lo humano. En un momento determinado el hombre de negocios le espetó al entusiasmado pensador inglés: "ideas, eso son solo ideas". A lo que el inglés replicó: "ideas, ¿solo ideas? ¿Sabe usted que con esas ideas un puñado de hombres confeccionaron una Enciclopédie y que la segunda edición de la misma se hizo con la piel de los que se habían reído de la primera?". Se refería lógicamente a los hombres ilustrados; la enciclopedia en cuestión era la que editaron Condorcet y D'Alembert y los que en ella escribieron, los famosos enciclopedistas, contribuyeron poderosamente a cambiar el mundo.

El primer fruto político de las ideas ilustradas fue la Declaración de los Derechos del 
convocada por el rey de Francia, Luis XVI, para levantar una nueva constitución a la altura de los tiempos. Los diputados entendieron que la nueva Carta Magna debía ir precedida de una declaración que empezaba así:

Los representantes del pueblo francés, constituidos en Asamblea Nacional, considerando que la ignorancia, el olvido o el desprecio de los derechos del hombre son las únicas causas de los males públicos y de la corrupción de los Gobiernos, han decidido exponer, en una declaración solemne, los derechos naturales, inalienables y sagrados del hombre, con el fin de que esta declaración, constantemente presente para todos los miembros del cuerpo social, les recuerde permanentemente sus derechos y deberes.

En el preámbulo se decía a los futuros legisladores que a la hora de tomar decisiones concretas debían atenerse a unos principios fundamentales cuyo olvido, desconocimiento o desprecio han sido la causa de todos los males políticos y de la corrupción de los gobiernos. Era esta una idea que venía de los Estados Unidos, más exactamente de la Declaración de Derechos del Buen Pueblo de Virginia, del 12 de junio de 1776, santo y seña de la revolución americana.

Estos principios, que amparan a los representantes del pueblo y a su posteridad y que son base y fundamento del gobierno, son los Derechos Humanos. La Asamblea Nacional francesa, "en presencia y bajo los auspicios del Ser Supremo", hace una enumeración solemne: que los hombres nacen libres e iguales en derecho, no aceptándose más diferencias sociales que las que convengan al bien común (artículo 1); que el principio de toda la soberanía reside en la nación, de suerte, nadie, ni individuo ni institución, disponen de más autoridad que la que emane de la nación (artículo 3); que la libertad consiste en hacer todo lo que no dañe a otro (artículo 4); que la ley es expresión de la voluntad general y que todos están llamados a participar según su capacidad (artículo 6); que todo hombre es inocente mientras no sea declarado culpable (artículo 7); que nadie debe ser molestado por sus opiniones, incluso las religiosas (artículo 10); que la sociedad puede pedir cuentas a todo funcionario público (artículo 15); que la propiedad privada, puesto que es un derecho inviolable y sagrado, es intocable a no ser porque lo exija la necesidad pública y siempre con una justa indemnización (artículo 17).

Sabemos por la historia que estos derechos irrumpieron en aquella Asamblea con tal fuerza que se llevaron por delante a la monarquía que la había convocado con el ánimo de encauzar las inquietudes sociales y las exigencias políticas de un pueblo que ya no aguantaba las reglas de juego del "antiguo régimen". Esos derechos inauguraban un tiempo revolucionario que acabaría decapitando al rey y derrumbando a la monarquía.

La pregunta que tenemos que hacernos es si con esa Declaración de los Derechos del Hombre y del Ciudadano todos los seres humanos empezaron a ser iguales, si se suprimieron las diferencias sociales producto de injusticias pasadas, si todos pudieron participar directa o indirectamente en la toma de decisiones, etc. Hay un hecho significativo que puede ayudar a dar una respuesta. Su protagonista 
es Robespierre, el severo líder revolucionario que mandó entre 1792 y 1794. Este hombre y los revolucionarios que le siguieron sabían que la revolución en curso tenía por objetivo principal la plena incorporación a una sociedad republicana -es decir, a una sociedad de libres e iguales - de los hasta entonces excluidos por una sociedad aristocrática y por un régimen absolutista. Entre ellos, había dos grupos bien diferenciados: por un lado, "el pueblo burgués", clase media acomodada; por otro, "el pueblo llano". Uno y otro estaban interesados en conquistar la dignidad republicana, a saber, ser respetados como seres humanos, ser sujetos de derechos y poner fin al vasallaje medieval que aún padecía, por lo menos el pueblo llano.

Lo que observaron los jacobinos es que uno y otro deseaban llegar al orden republicano pero de manera distinta: mientras que al "pueblo burgués" lo que le interesaba era lo suyo, su incorporación, esto es, acabar con las rigideces, los privilegios, las cargas y las barreras del viejo régimen que les impedía su pleno desarrollo económico y social, ocurría que al "pueblo llano" lo que le interesaba era acabar con toda exclusión, consciente de que si el sistema disponía de una rendija para la desigualdad y la esclavitud, habría esclavos y desiguales.

El temor del "pueblo llano" de que la ola revolucionaria solo alcanzara a la burguesía empezó a confirmarse pronto. Pronto apareció claro, en efecto, que la igualdad y la libertad revolucionarias se traducía por "libre ejercicio de la industria y del trabajo". Cuando el pueblo quiere aplicarse las consignas revolucionarias, mediante protestas porque no les llega para comer, se les responde con la represión. El pueblo ha quedado excluido de los ideales revolucionarios.

Robespierre aprovechó un debate sobre la composición social del nuevo ejército revolucionario, llamado Guardia Nacional, del que se quería excluir a los desposeídos porque no eran de fiar, para denunciar lo que estaba ocurriendo. El líder jacobino se preguntaba si las nuevas leyes "no han sido establecidas para proteger a la debilidad contra la injusticia y la opresión... Pero los ricos... han pretendido que sólo los propietarios son dignos del nombre de ciudadanos" (Domenech, 2005).

Para la República que anunciaba la Revolución francesa todos eran ciudadanos, también los pobres. Y para dejar bien claro que los ideales revolucionarios de libertad e igualdad a los que se refiere la Declaración de 1789 cobijaban también a los pobres, añadió a la égalité y liberté, el tercer miembro de la trilogía revolucionaria: fraternité. La fraternidad estará siempre ahí para recordar que los pobres también son libres e iguales.

El término está bien pensado. La fraternidad evoca la idea de que la sociedad es una familia y los hombres son hermanos. Si tenemos en cuenta que durante siglos ha dominado una "ley de familia", en virtud de la cual algunos de sus miembros eran tratados como esclavos, el término de fraternidad exige para esos excluidos por la sociedad medieval pleno reconocimiento de sus derechos, tenemos que reconocer la novedad y provocación que llevaba consigo el término en cuestión. Para el pueblo llano, a partir de ese momento, "hermanarse" era un 
gesto reivindicativo de gran valor: equivalía a emanciparse de la tutela a la que había estado sometido hasta entonces.

La fraternidad no tiene límites, por eso se habla de "fraternidad universal". Hermanos son no solo los pobres de casa, sino también los esclavos de lejos y los colonizados por el imperio francés. Por eso, la fraternidad revolucionaria es inmediatamente traducida en abolición de la esclavitud y en renuncia a la conquista militar. "La más extravagante de las ideas que puede nacer en la cabeza de un político", dice Robespierre:

es creer que basta que un pueblo entre a mano armada en un pueblo extranjero para que éste adopte sus leyes y su constitución. Nadie quiere a los misioneros armados, y el primer consejo que dan la naturaleza y la prudencia es rechazarlos como enemigos.

"Los hombres nacen y permanecen libres e iguales" decía el artículo primero de la Declaración de 1789. Como el artículo estaba en peligro de quedar en papel mojado, Robespierre y los suyos se encargaron de hacerlo realidad, por eso abolieron la esclavitud, renunciaron a las guerras coloniales, consideraron ciudadanos a los desposeídos e impusieron el sufragio universal. Todas estas explicitaciones era lo que sobreentendían con el término "fraternidad". Pues bien, contra esa ambiciosa democracia fraternal se sublevaron el 8 de termidor de 1794 fuerzas sociales y políticas que dieron al traste con el Estado jacobino, bajo el lema "es evidente que los propietarios, sin cuyo permiso nadie podría conseguir en el país alojamiento y manutención, son los ciudadanos por excelencia".

Los nuevos revolucionarios abolieron el sufragio universal, volvieron las guerras de conquista de la mano de Napoleón y las prácticas esclavistas. A la vuelta de una de esas guerras, el 18 brumario de 1799, Napoleón dio un golpe de Estado inaugurando el llamado Consulado, en el que quedarían sepultadas la mayoría de las conquistas ganadas por la fraternidad.

Toda la historia posterior a la fraternité, es decir, a la universalización de las conquistas revolucionarias (igualdad y libertad), va a ser una lucha entre quienes se oponen y quienes se defienden. Lo nuevo es que esa oposición tiene como epicentro la propiedad. Lo decía tempranamente un agudo observador de lo que estaba pasando, Tocqueville:

Muy pronto la lucha política se entablará entre los que poseen y los que no poseen; el gran campo de batalla será la propiedad, y las principales cuestiones de la política discurrirán sobre las modificaciones más o menos profundas que habrá de sufrir el derecho de los propietarios (Domenech, 2005, p. 115)

Ahora ya sabemos qué hace que uno sea libre e igual: el título de propiedad. Habrá episodios en los que el pueblo llano se una al pueblo burgués para luchar juntos contra algún monarca absolutista, como ocurrió en 1830 y 1848, pero a partir de ese momento, los campos estuvieron definidos por la propiedad. De un lado, los que poseen, aunque sean unos volterianos y otros eclesiásticos; por otro, los 
desposeídos, que no tendrán inconveniente en aliarse con cristianos sensibles a la "cuestión obrera".

En todo ese tiempo, el término "fraternidad" fue como un resorte eficaz. Para los revolucionarios socialistas de 1848, la palabra iba asociada a la recuperación del sufragio universal, la supresión de la esclavitud en las colonias o el reconocimiento de los derechos de la mujer. Para los otros, los llamados "gens du bien" (que se oponían a la "gens du rien") la palabra producía salpullidos. Un panfleto de 1848 respondía a la pregunta ¿qué es la fraternidad? de la manera siguiente: "la necesidad generalmente sentida por el pobre de saquear la fortuna del rico y si es preciso, de matarle".

Desde el momento en que la igualdad y la libertad se plantea en el terreno económico, la invocación a la fraternidad no basta. No bastan las declaraciones cuando los condicionantes son materiales. Llevar la igualdad al terreno económico significa dar un contenido material a la fraternidad. Lo que se impone entonces es cambiar o crear las condiciones materiales para que la libertad o la igualdad dejen de ser palabras vanas. Mientras no se abordaran esos problemas, la burguesía podía mofarse de la fraternidad. Había que pensar en fórmulas más eficaces de cofraternización. Eso es lo que comprendió bien el socialismo y a eso se refería en este texto Karl Marx al criticar el recurso al término "fraternidad" como si fuera una palabra mágica capaz por sí misma de superar las diferencias económicas y sociales que dividían y enfrentaban a los seres humanos. Escribe:

\footnotetext{
La fraternidad - esa cómoda abstracción de los conflictos de clase, esa sentimental nivelación de los contradictorios intereses de las clases, esa ilusoria elevación por encima de la lucha de clases - fue el verdadero santo y seña de la Revolución de Febrero (se refiere a la revolución de 1848)... El proletariado parisino se disolvió en los goce de esa generosa embriagadez de fraternidad (Domenech, 2005, p. 122).
}

Lo que está diciendo Marx es que los obreros parisinos se pusieron del lado de la burguesía; juntos lucharon contra el gobierno despótico de turno. Cuando lo consiguieron, celebraron ese encuentro como un gran momento de fraternización. Pero pronto se dieron cuenta de que la burguesía había tratado a los obreros de "hermanos" solo mientras luchaban a su lado. Una vez hecho el trabajo y dejado el gobierno en manos de sus compañeros de armas, los burgueses las volvieron contra los obreros, sus enemigos de clase.

Si durante un tiempo el enfrentamiento social parecía ser entre modernos y antiguos, entre laicistas y clericales, es decir, entre los que se sentían ilustrados porque confiaban en la razón y los que añoraban la autoridad de la religión y del príncipe, ahora cambian las cosas o, mejor dicho, muestran su verdadero rostro. Ahora resulta en efecto que la verdadera división es entre ricos y pobres, entre poseedores y desposeídos, por eso se une la burguesía volteriana con la clerecía más reaccionaria. Un caso emblemático es el político liberal Thiers, antiguo comecuras, que ahora busca el apoyo de la iglesia. Este político ve peligro en el afán educador de esos "pequeños institutores laicos" que quieren insuflar en los obreros 
el espíritu republicano cuando lo que hay que enseñarles son sencillamente las cuatro reglas. Pide entonces que "le traigan a hermanos de las escuelas cristianas", a los que persiguió en otro tiempo, pero que ahora estima sobre todo, pues saben "propagar esa buena filosofía que enseña al hombre que está aquí para sufrir". Y otro colega suyo, de la misma camada liberal, Louis Veuillot, apostilla: "la sociedad tiene necesidad de esclavos; no puede subsistir más que a ese precio. Es necesario que haya hombres que trabajen mucho y vivan perramente".

El rechazo frontal de los gobiernos burgueses parlamentarios a las demandas obreras confirmó a los trabajadores que lo que esos estados ofrecían a los obreros no era una carta de ciudadanía sino algo parecido a una "dictadura de clase". Vivían en una polis que no les reconocía como ciudadanos porque les hurtaba la participación en la política y también las condiciones mínimas de existencia. Solo encontraban ayuda y solidaridad entre los de la misma condición. Aparecía así la mentalidad de la "lucha de clases" y desaparecía la idea de una nación, de una patria común, de unas instituciones que fueran de todos. Los obreros tuvieron entonces que crear sus escuelas, sus economatos, sus centros culturales, sus editoriales, sus periódicos y hasta sus bancos.

Solo poco a poco se reconciliaron con las instituciones ciudadanas hasta entonces patrimonializadas por la burguesía. Fue cuando experimentaron que la acción política dentro del Estado burgués daba resultados; que además de la revolución había sitio para reformas graduales que mejoraran su suerte. Eso unido a la desastrosa experiencia de los totalitarismos del siglo XX, tanto del fascismo como del estalinismo, en los que no cabía el socialismo democrático, explica la asimilación por el socialismo de las instituciones civiles. Para ese socialismo, el Estado tiene que ser de Derecho - es decir, basado en el respeto a las libertades individuales - y además Social, esto es, consciente de que tiene que contribuir a mejorar la situación material de los más pobres. El Estado Social de Derecho es un valor en sí mismo, un patrimonio irrenunciable que tiene mecanismos, además, para avanzar en la mejora de las condiciones de vida de los menos favorecidos. De esta suerte, el socialismo de la socialdemocracia moderna se reconcilió con el concepto de ciudadanía, dándole el añadido de preocupación social.

\section{Conquista de los Derechos Humanos}

La Declaración americana de Virginia de 1776 y la Declaración de los Derechos del Hombre y del Ciudadano, de 1789, son hitos en la historia de los Derechos Humanos que son la auténtica carta magna de la ciudadanía. Conviene tener en cuenta que esos derechos no son fruto de un manifiesto, escrito por algún iluminado, sino conquistas arrancadas a los poderes del momento con muchos sacrificios. Bien podemos decir que estamos ante un proceso que no ha terminado aún.

Esa historia de lucha viene de muy lejos. Un ejemplo puede iluminar lo que se quiere decir. En 1510, diecinueve años después de la llegada de Colón, una modesta comunidad de dominicos recién llegados a La Española vieron cómo la 
conquista americana por los españoles producía muertes, asesinatos, explotación y violación de todos los derechos divinos y humanos. Deciden entonces denunciar con un sermón a cargo de uno de ellos, de Antón Montesinos:

\begin{abstract}
¿con qué derecho y con qué justicia tenéis en tan cruel y horrible servidumbre a estos indios?, ¿con qué autoridad habéis hecho tan detestables guerras a estas gentes que estaban en sus tierras mansas y pacíficas?, ¿cómo los tenéis tan opresos y fatigados, sin darles de comer ni curarles de sus enfermedades? (Gutiérrez, 2003, p.46).
\end{abstract}

Detrás de esas preguntas están la experiencia de la esclavitud, de la violencia ilegítima de la conquista, del maltrato inhumano de los encomenderos. Cierto es que esas preguntas indignadas nacen de la idea de ser humano que tienen estos misioneros y que no es compartida, de ahí su última pregunta: "¿acaso no son hombres?". Más aún. "¿no estáis obligados a amarlos como a vosotros mismos?". Para muchos, los indígenas no eran humanos, al menos en el sentido que ellos lo eran. Como les consideraban seres humanos inferiores, podrían tratarles como esclavos.

Fruto de la reflexión de muchas generaciones sobre el maltrato del ser humano por el ser humano es la conciencia, reflejada en las declaraciones de 1776 y de 1789, de que todos los seres humanos somos iguales en dignidad. Nace entonces la primera generación de Derechos Humanos conocidos como derechos de la libertad o derechos civiles. Su intención es proclamar el valor del individuo y de sus libertades ante la intromisión injustificada de los poderos políticos, religiosos o económicos. Los primeros derechos reconocidos son los de las libertades: libertad de religión, libertad de expresión, derecho de propiedad, derecho a la seguridad, derecho a tener un juicio justo.

Con esta primera generación de derechos se afirma que todos los hombres son iguales en la libertad o iguales ante la ley que protege las libertades. No era todo pero era mucho. Con esos derechos no hubiera sido posible, por ejemplo, la conquista de América, tal y como querían los dominicos de La Española y tal como no cesó de predicar Bartolomé de Las Casas, el heredero del "espíritu de Montesinos". Digo que no era todo porque ni siquiera entonces se reconocían esos derechos a todos los seres humanos. Los mismos, en efecto, que proclamaron esos derechos, se los negaban a los esclavos, o a los pobres o a las mujeres. Los Estados Unidos tenían, sí, una constitución que proclamaba la libertad como un derecho universal pero no abolió la esclavitud. Quienes entonces se pusieron a hablar de fraternidad lo que querían era que se tomara en serio la libertad para todos.

Ya hemos visto cómo pronto la prédica de la fraternidad no fue suficiente. Había que dar un paso más. Era necesario completar esa primera generación de Derechos Humanos con los derechos de la igualdad. No de la igualdad en la libertad, sino de la igualdad material, al menos en lo fundamental. Sin unas condiciones generales de igualdad mínima en educación, en la seguridad social, en la protección de la salud, en el trabajo y en la vivienda, de poco servía proclamar la igualdad en la libertad. Es la hora de los derechos sociales que serán recogidos en la solemne Declaración 
de los Derechos Humanos de 1948. Sin esos derechos materiales no hay justicia posible ni ciudadanía real.

Hay que señalar, finalmente, que estamos asistiendo a la emergencia de la tercera generación de Derechos Humanos, que se suman a los conseguidos por las dos grandes tradiciones de occidente: la liberal y la social. Son los llamados derechos de la solidaridad, que tratan de responder a los grandes retos de nuestro tiempo: la amenaza de la guerra total y del terrorismo internacional; la amenaza de los desastres ecológicos; la amenaza que suponen las enormes diferencias entre países pobres y ricos y finalmente la amenaza del desarrollo tecnológico que pone en peligro nuestro derecho a la intimidad e incluso a una muerte digna. Pues bien, los derechos de la solidaridad responden a esos peligros con la proclamación del derecho a la paz; a la preservación del medio ambiente, pensando en el mundo que dejaremos a nuestros nietos; a una justicia global y al uso de la ciencia y de la tecnología al servicio de los seres humanos y no al revés.

\section{La fragilidad de los Derechos Humanos.}

Los Derechos Humanos han sido una gran conquista porque consiguieron situar la dignidad humana no en la cuna sino en el nacimiento, en el mismo momento del nacimiento. A partir de ese momento, la ciudadanía era el despliegue de la dignidad humana con la que todos y cada uno de los humanos vienen al mundo. Pero una vez dicho esto conviene no perder de vista la gran fragilidad de los Derechos Humanos. Basta echar una mirada a nuestro alrededor o a las noticias para darnos cuenta de que siguen brillando por su ausencia en muchos lugares del mundo: aún hay esclavos, niños y niñas esclavizadas; pese a que nunca el mundo fue tan rico, siguen aumentando los pobres hasta el punto en que cerca de 18 millones de seres humanos mueren de hambre cada año, sigue la carrera armamentística y el expolio de los mares, la polución del aire y el envenenamiento de la tierra.

Lo que hay que decir enseguida es que esa fragilidad de los Derechos Humanos es congénita. La Declaración de 1789 decía en su primer artículo que "Los hombres nacen y permanecen libres e iguales". Somos libres por nacimiento, por el mero hecho de nacer humanos. Pero ya el artículo tercero recorta esa generosa afirmación al decir que "el origen de toda soberanía reside esencialmente en la nación". ¿Entonces qué hay de nuestras exigencias?, ¿deben someterse y compaginarse con lo que cada nación decida? Ahí se anuncia un conflicto entre los derechos del ser humano y los papeles que da el Estado. Si resulta que los contenidos de los derechos se obtienen con la venida al mundo, los Estados solo tendrían que confirmarlos; pero si los derechos en cuestión se obtienen por ser miembro de un Estado, entonces de poco valen los derechos si no vienen acompañados de papeles.

Este no es un debate teórico. Entre las dos grandes guerras mundiales nacieron en Centroeuropa muchos Estados basados en las raíces étnicas mayoritarias. Las minorías que no pertenecían a esas etnias fueron desnacionalizadas y convertidas 
en apátridas. Entonces hicieron la experiencia de lo que significa andar por el mundo sin más dignidad que la de ser humano: era no ser nada. Era mucho más rentable ser delincuente que apátrida inocente, pues el delincuente estaba sometido a las leyes del Estado, leyes que le condenaban, efectivamente, pero también que en ese acto de sanción le consideraban sujeto de derechos. Lo peor era ser considerado apátrida o refugiado porque era lo mismo que decir superfluo, que estar de más. Lo que esta gente experimentó, antes y después de la guerra, es que es no es lo mismo ser humano que ser ciudadano: era mucho más importante ser miembro de una nación, de una comunidad, que ser merecedor de los derechos solemnemente declarados por la ONU, y antes por los revolucionarios americanos y franceses. Como dijo en una ocasión un ministro español de Asuntos Exteriores, Abel Matutes, a propósito de una estampida xenófoba en un pueblo almeriense: "para el Estado el emigrante sin papeles, no existe". Entiéndase bien, existe como mano de obra, como brazo de trabajo sin cuerpo humano, pero no como sujeto de derechos. Eso solo se consigue en el momento en el que el Estado le otorga los documentos.

Hoy como ayer, quien solo dispone de los Derechos Humanos preferiría canjearlos por la de ser miembro de un Estado, porque sabe por experiencia que es mucho más grave la pérdida de la nacionalidad que la violación de los Derechos Humanos. En efecto, cuando uno pierde la nacionalidad, pierde su pertenencia a la condición humana, cuando uno pierde su hogar, pierde el derecho a tener hogar, cuando uno pierde la protección de su gobierno queda incapacitado para conseguir la de otro.

Lo que esto significa es que la historia ha quedado atrapada por el artículo tercero. Para que fuera efectivo el artículo primero - a saber, "que todos los hombres son por naturaleza igualmente libres e independientes y tienen ciertos derechos innatos de los que, cuando entran en estado de sociedad, no pueden ser privados...". (Declaración de Virginia de 1776) - habría que disponer de un gobierno a la altura de la naturaleza humana, es decir, un gobierno mundial que vigilara y sancionara el cumplimiento de estos derechos innatos. Pero el único gobierno que conocemos es el de la nación - el del Estado-nación o el de una asociación de Estados-naciones como pueden ser la Unión Europea o la misma ONU - . Estamos pues lejos de un poder derivado de la naturaleza humana.

Muchos piensan que, pese a todo, hay que seguir hablando y defendiendo los Derechos Humanos porque, aunque no puedan imponerse por sí mismos, son una especie de conciencia moral mundial que saca los colores al país, grupo humano o persona individual que no los respete. Sin olvidar, por otra parte, que el espíritu que los anima ha ido encarnándose en muchas disposiciones de los Estados, los cuales sí son eficaces. Gracias a los Derechos Humanos se ha creado, por ejemplo, el Tribunal Penal Internacional, que persigue a los genocidas doquiera que estén; o se han establecido unos principios en bioética que guían las investigaciones y las prácticas médicas en estos campos. 
Es verdad que los Derechos Humanos están resultando útiles al ser humano, pero habría que ser conscientes de que estamos ante un territorio aún inseguro que necesita grandes clarificaciones, también teóricas, para no caer en el autoengaño.

Señalaré, para terminar, dos extremos que exigen una reflexión más profunda. El primero lo tomo de Walter Benjamin. Este pensador se pregunta cómo es posible que digamos que los seres humanos somos iguales o libres, por nacimiento, cuando no lo somos, pues unos nacen herederos de fortunas y otros de infortunio. ¿En qué humano estamos pensando cuando decimos que nacemos iguales y libres y no es así? Evidentemente, no es el ser de carne y hueso que en su inmensa mayoría no queda afectado por los famosos Derechos Humanos. Estamos pensando en un ser abstracto, claro, o en tal y como debiera ser. Lo que en el fondo pensamos es que el ser humano debería ser tratado como igual y libre, etc. Para decirlo en la jerga filosófica, el sujeto de los Derechos Humanos no es el hombre real sino un hombre transcendental, que es una construcción ideal, cuyo inconveniente es que no existe.

Lo que es realmente preocupante no es esa construcción ideal del ser humano, que vale como utopía, sino el que no demos importancia al ser humano real que nace desgraciado. Si resulta, en efecto, que seguimos predicando la igualdad y la libertad en el ser humano por el hecho de nacer humano, aunque no sea ni libre ni igual, es porque pensamos que poco importa la situación real del ser humano a la hora de hacer una teoría sobre el ser humano. Cuenta más la idea que nos hacemos del hombre que su situación real. Y eso sí que es preocupante porque si nos importaran mucho los Derechos Humanos -y nos deben importar por lo que se juega en ellos-, entonces deberíamos reconocer que la igualdad es una tarea pendiente, una meta que tenemos que conquistar y no un hecho.

El segundo punto quiere señalar lo difícil de esa tarea. Hay Derechos Humanos - me refiero a los derechos de la libertad - que no se cumplen porque hay Estados totalitarios o corruptos que se oponen a los derechos más elementales. Otros derechos - los derechos de la igualdad - no se cumplen porque los Estados son pobres o no tienen medios para cumplirlos. Y otros - los derechos de la solidaridadque no se cumplen porque van contra nuestros intereses y nuestras convicciones más profundas. De esto es de lo que hay que hablar.

Esta tercera generación de derechos - derecho a la preservación del medio ambiente y, de una manera más general, a la vida del planeta - se topan con el progreso, de suerte que estos Derechos Humanos con quien tienen que vérselas no es contra Estados corruptos o pobres, sino contra nosotros mismos. Lo que llama la atención es la sensibilidad existente sobre estos problemas. Los ecologistas, que hace 30 años eran vistos como radicales agoreros de desgracias inventadas, son ahora escuchados con ansiedad porque hemos empezado a experimentar sobre nuestras propias carnes la verdad de sus peores augurios.

El planeta Tierra muestra síntomas de agotamiento no por los años que lleva dando vueltas alrededor del sol sino por el daño que le hacemos los seres humanos. Enumeremos algunos de estas señales de peligro: 
La brutal deforestación de Amazonia. En tres siglos de colonización se talaron unos 100 km2; pues bien, en tan solo 13 años de dictadura militar la de forestación alcanzó los 300.000 km2 y la cosa sigue a ese ritmo. Si en 1950, el 30\% de la superficie terráquea era bosque, hoy no llega al $5 \%$.

El galopante avance de la desertificación del planeta que anuncia los cambios climáticos que ya conocemos.

El agotamiento de recursos y la destrucción de la biodiversidad. La Tierra es rica, pero sus recursos son limitados. Como decía Gandhi: "nuestro planeta ofrece todo lo que el hombre necesita, pero no todo lo que el hombre codicia". Cada día desaparecen unas cuarenta especies animales y vegetales. La disminución de la capa de ozono, la barrera protectora de nuestra atmósfera contra las radiaciones ultraviolentas del sol. La contaminación del agua, del aire, del mar y de la tierra. La carrera armamentística o la superpoblación del planeta.

A la vista de lo que está ocurriendo, caben dos salidas: asumir resignadamente, como algunos piensan, que "la meta final del hombre es la abolición del hombre". Parafraseando al Makoki, habría que decir que el lema del ser humano es "de victoria en victoria hasta el fracaso final". O bien, confiar en la capacidad ética del ser humano, capaz de dar un volantazo en los momentos de peligro y decir basta. El poeta Hölderlin decía que "cuando se acerca la salvación aumenta el peligro"; ha llegado la hora de invertir los términos y decir: "cuando aumenta el peligro, crece la necesidad de salvación". En enero de 2007 la prensa mundial se hizo eco de unas declaraciones de varios científicos, entre ellos, el cosmólogo británico Stephen Hawking, que resumían así el estado de la cuestión:

\footnotetext{
Mientras nos acercamos al borde de una nueva era nuclear y a un período de cambio climático sin precedentes, los científicos tienen una vez más la responsabilidad de informar sobre los peligros que afronta la humanidad. Prevemos un gran riesgo si los gobiernos y las sociedades no actúan para dejar obsoletas las armas atómicas y para frenar el cambio climático.
}

Parecería lógico que el ser humano decidiera salvarse. Lo que tenemos que reconocer es que la salvación no es cosa exclusiva de los políticos, ni de que cumplan los protocolos de Kioto. El problema somos nosotros mismos o, más exactamente, nuestra idea de progreso. El progreso goza de un indiscutible prestigio. Cualquier político que se precie de serlo dirá que su programa es "de progreso". Ese prestigio tiene que ver con la mentalidad moderna. Cuando esta irrumpe en el siglo XVIII en Europa, se presenta como lo opuesto al "antiguo régimen" empeñado en conservar las cosas, en impedir el cambio, en hacer valer la tradición y el pasado. Los modernos, por el contrario, quieren inventar la realidad, creen en la novedad y prometen un mundo nuevo. Para ello tienen que dar la espalda al pasado y entregarse al progreso. Recordemos cómo influye esto en la universidad. Durante siglos, la universidad era el lugar donde se transmitían los saberes, es decir, se pasaba a las nuevas generaciones lo que las viejas habían recibido de sus mayores. Pero se pensaba que los contenidos eran siempre los mismos: philosophia peremnis. 
La universidad moderna, ideada por el ilustrado Humboldt, nació bajo el convencimiento de que la universidad que no investiga no sabe enseñar. El acento se pone en el descubrimiento de saberes pero empezando por los profesores. Hay que enseñar sobre todo lo que se descubre y no solo lo que se recibe. Todo esto es inobjetable ¿Cuál es, entonces, el problema? Esta manera de ver las cosas trajo un desarrollo espectacular en la ciencia y, consecuentemente, en la tecnología, en la industria, en la economía, en la medicina, etc. del que se ha beneficiado una parte de la humanidad. Pero ha tenido un costo muy elevado: el desarrollo industrial del siglo XIX se hizo en buena parte gracias a la universalización del esclavismo; se están agotando los recursos energéticos; hemos contaminado el agua, el aire y la tierra; la tierra está amenazada en su existencia por armas que nosotros mismos hemos creado.

Todo eso es progreso - la llegada del ser humano a la luna y la construcción de la bomba atómica - de ahí que tengamos que preguntarnos sobre la calidad del progreso. Esa pregunta puede ser formulada así: ¿está el progreso al servicio de la humanidad o la humanidad al servicio del progreso? No es lo mismo. Si la humanidad está al servicio del progreso, entonces será bueno todo lo que haga avanzar el conocimiento. Lo demás será secundario. Por "demás" hay que entender dos cosas: en primer lugar, el contenido de lo que se investigue. Da lo mismo inventar la bomba atómica que descubrir una vacuna que salve vidas. Lo importante es conquistar nuevos mundos para el conocimiento. En segundo lugar, no debe importarnos el costo humano y social del progreso. Si hay que hacer una guerra para probar las nuevas armas, se hace. Debería dar de qué pensar el hecho constatado de que el motor de la investigación en el siglo XIX (sobre todo en la química) y en el siglo XX (sobre todo en la física) haya sido la guerra. Otra cosa muy distinta es si el objetivo del progreso es la humanidad. En este caso, el progreso es un medio al servicio de la humanidad y será el hombre el que marque, por ejemplo, las prioridades de la investigación. Entre financiar el descubrimiento de un arma más letal o una vacuna que salve vidas, optará por la vacuna. No descartará la investigación farmacéutica en enfermedades que afecten a sectores pobres de la población porque le será menos rentable, sino que medirá su importancia en función de los beneficios humanitarios que se deriven. Y así sucesivamente.

Esta crítica al progreso no significa por tanto negarle, ni abogar por la vuelta al candil. De lo que se trata es de saber si el progreso es para cada uno de nosotros fin o medio. Digo "para cada uno de nosotros" porque de lo que hay pocas dudas es de que el progreso es, para nuestro tiempo, el gran objetivo, la meta, el dios al que todo se inmola. Por eso precisamente hemos llegado al punto de peligro en el que nos encontramos. No pensemos que esta situación es cosa de hoy. Viene de lejos. Ya a mediados del siglo pasado hubo quien se dio cuenta de que la lógica del progreso llevaba al desastre. La humanidad había saludado la irrupción de la ciencia y de la tecnología, en el siglo XIX, porque creían ingenuamente que se iban a multiplicar las riquezas de tal manera que por fin se podrían realizar los viejos sueños de felicidad de la humanidad. Pero los espíritus más agudos pronto vieron que el nuevo mundo no era para el hombre. Comprendieron que el ser humano había desencadenado un proceso que, como en la Colonia Penitenciaria de Kafka, 
amenazaba a su propio creador. Uno de ellos hizo entonces el diagnóstico más certero que sigue vigente:

\begin{abstract}
Marx dice - escribía Walter Benjamin en 1939- que las revoluciones son las locomotoras de la historia universal. Pero quizá sean las cosas de otra manera. Quizá consistan las revoluciones en el gesto, ejecutado por la humanidad que viaja en ese tren, de tirar del freno de emergencia.
\end{abstract}

Un progreso al servicio de la humanidad exige que hagamos un alto, que detengamos el tren en marcha, que revisemos la lógica de progreso que invade la política, la economía y hasta la cultura de nuestro tiempo si no queremos ir a la catástrofe. Hoy el contenido de la palabra "revolución" no remite a aceleración del tiempo, sino a interrupción de la lógica del progreso. Bertolt Brecht, que captó la gravedad del momento y también la incapacidad de reacción, escribió: "cuando llega el crimen, cuando cae la lluvia, ya nadie dice ¡basta!". A nosotros, hombres y mujeres del siglo XXI, nos parecen de otro mundo las palabras del jefe indio Seattle, pronunciadas en 1856 ante el gobernador de Washington que quería comprarle tierras: "cada parte de esta tierra es sagrada para mi pueblo. Somos parte de la tierra. La tierra no pertenece al hombre. Es el hombre el que pertenece a la tierra". Nos suenan extrañas y son quizá palabras salvadoras.

El ciudadano del siglo XXI no puede esperar pasivamente a que se den las condiciones para la puesta en práctica de los Derechos Humanos de las distintas generaciones. Tiene que ubicarse junto al freno de emergencia y tratar de parar el tren que camina desbocadamente y no precisamente hacia la felicidad.

\title{
Bibliografía
}

Beuchot, M. (1994). Los fundamentos de los Derechos Humanos en Bartolomé de Las Casas. Barcelona: Anthropos.

De Las Casas, B. (1957-58). Historia de las Indias. Obras Escogidas II. BAE.

Domenech, T. (2005). El eclipse de la fraternidad. Madrid: Debate.

Gutiérrez, G. (2003). En busca de los pobres de Jesucristo. El pensamiento de Bartolomé de las Casas. Lima: Cep.

Kant, E. (1988). ¿Qué es la Ilustración? "Respuesta a la pregunta ¿qué es la Ilustración?" Madrid: Tecnos.

Reyes Mate, M.. (2006). Medianoche en la historia. Comentarios a las tesis de Walter Benjamin sobre el concepto de historia. Madrid: Trotta.

Platón. Diálogos. (Protágoras). Madrid: Biblioteca Clásica, Gredos.

Reyes Mate, M. (1973). El ateísmo problema político. Salamanca: Sígueme.

Sánchez Ron, J. M. (1992). El poder de la ciencia. Madrid: Alianza.

Tucídides (2000). Historia e la Guerra del Peloponeso. "Discurso Fúnebre de Pericles". Madrid: Gredos. 